\title{
Küçük Yerleşim Yerlerinin Turizme Açılmasında Kültürel Mirasın Rota İle Kurgulanması
}

\author{
Hicran Hanım HALAÇ ${ }^{1 *}$, Merve BENZER ${ }^{2}$ \\ ${ }^{1}$ Eskişehir Teknik Üniversitesi, Mimarlık Fakültesi Fakültesi, Mimarlık Bölümü, Eskişehir \\ (hhalac@anadolu.edu.tr) ORCID ID 0000-0001-8046-9914 \\ ${ }^{2}$ Eskişehir Teknik Üniversitesi, Fen Bilimleri Enstitüsü, İleri Teknolojiler A.B.D. Kültür Varlıklarının Belgelenmesi \\ Yüksek Lisans Öğrencisi, Eskişehir \\ (merve.benzer@hotmail.com) ORCID ID 0000-0001-7140-4983
}

$\ddot{O} z$

Günümüz dünyasında insanların toplumsal yaşantı içerisinden uzaklaşıp yoğun seyahat etme arzusu ve yeni yerler keşfetme hali içerisinde olduğu bilinmektedir. İnsanların yoğunluklu olarak kıyı kesimlere ve büyük ölçekli kentlere olan ilgisinin temelinde bu kentlerin turizm açısından gelişkin olduğu ve tanıtımının yoğun bir şekilde yapıldığı gözlenebilmektedir.

Kültürel miras açısından zengin çeşitliliğe sahip olan ülkemizde kentler kendine has özellikler ve dokular barındırmaktadır. Turizm amaçlı hareketlerde kültürel mirasın gezi rotası ile kurgulanması, kentlerin farkındalığının arttırılmasını ve kültürel mirasın tanıtılmasını sağlayacaktır. Külttürel mirasın kent etkileşimi ile ele alınması kentin kendine özgü yerel özelliklerinin ve yaşam biçiminin nesilden nesile aktarılmasına ve kültürel faaliyetlerin gelişmesine neden olacaktır.

Bu çalışmada küçük ölçekli Anadolu kentlerinin somut ve somut olmayan kültürel miras ögelerinin kendine özgü özelliklerinin farklı kültür rotaları oluşturularak turizme açılması ve bu kentlere olan ilginin arttırılması amaçlanmıştır. Bu bağlamda oluşturulacak kültür rotaları ile kentlerin kendine özgü yerel-kültürel özelliklerini dönüştürmekten kaçınarak kentlerdeki kültürel miras dokusunun özgün niteliğinin korunması ve ziyaretçilerin bilgilendirilmesi amaçlanmıştır.

Çalışmada literatür araştırması yöntemi izlenmiştir. Literatür araştırmasında Dünya'da ve ülkemizde yapılmış çalışmalar incelenmiş, benzerlik ve karşıtlık ilişkileri geliştirilerek yorumlanmıştır. Çalışmada elde edilen bulgular doğrultusunda kültürel mirasın korunması kadar tanıtımının da öneminin olduğu, kültür turizminin ülkemiz açısından önemi ve geliştirilmesi gerektiği sonucuna ulaşılmıştır. Tüm bunlar 1şığında küçük ölçekli kentlerde bulunan kültürel çeşitliliğin kültür rotaları planlamalarıyla dışarıya açık bir hal alabileceği ve büyük ölçekli kentlerdeki ilgiyi içerisinde barındırabileceği sonucuna ulaşılmıştır.

Anahtar Kelimeler: Gezi, Kültürel Miras, Kültür Turizmi, Rota, Turizm

\section{Mapping Out The Cultural Heritages By A Route In The Opening Of Small Settlement Areas To Tourism}

\begin{abstract}
In today's world, people are known to have desire to travel extensively and explore new places by moving away from social life. It is observed that what lies beneath people's particular interest in coastal areas and large-scale cities is such cities' being developed in views of tourism and their widespread publicity.
\end{abstract}

\footnotetext{
* Sorumlu Yazar
} 
In our country, which has rich diversity in terms of cultural heritage, cities have their own distinguishing features and textures. Mapping out the cultural heritage by a trip route in tourism activities will help increase the awareness of the cities and promote the cultural heritage. Handling cultural heritage through city interaction will enable the city's unique local characteristics and lifestyle to be handed down from generation to generation, improving cultural activities.

In this study, it has been aimed at increasing the attention to small-scale cities and offering such cities to tourism by establishing different cultural roots of the distinguishing features in tangible and non-tangible cultural heritage of Anatolian cities. In this context, it is aimed at protecting the original quality of the cultural heritage texture of the cities and keeping informed visitors thanks to cultural routes to be created, avoiding transforming the distinguishing local-cultural features of the cities.

Literature search method has been employed in the study. In this literature search, the studies conducted in our country and around the world have been examined and discussed on the basis of comparison and contrast relations. Based on the study results obtained, it has been concluded that the publicity of the cultural heritage is as significant as the protection of it, that cultural tourism is of utmost importance in views of our country and it should be further improved. In the light of these findings, the cultural diversity, present in small-scale cities, can be outward oriented thanks to cultural route planning, thus involving interest in large-scale cities.

\section{Keywords: Cultural heritage, Cultural Tourism, Route, Trip, Tourism}

\section{GİRIŞ}

Çok katmanlı ve mozaik bir yapıya sahip olan ülkemiz, doğal güzellikleri ve kültürel miras ögeleri bakımından farklı özellikteki birçok katmanı içerisinde bulundurmaktadır. Bu çok katmanlı yapı içerisinde insanların yeni yerleri keşfetme isteği turizm faaliyetlerinin gelişimini önemli bir noktada etkilemiştir. Bu anlamda son yıllarda hızla gelişen alternatif turizm ön plana çıkmaktadır.

Albayrak'a göre alternatif turizmin amac1 "İnsanların her geçen gün farklılaşın seyahate ilişkin beklentilerine daha iyi cevap vermek ve ülkelerin turizme kaynaklık edecek potansiyellerini daha iyi kullanmalarını sağlamak ve bu yolla ekonomik, sosyal ve kültürel kazanımlarını arttırmak” şeklindedir (Albayrak, 2013. s.12).

Alternatif turizm içerisinde zamanla farklı çeşitlilikler ortaya çıkmıştır. $\mathrm{Bu}$ çeşitlilik içerisinde kültür turizmi önemli bir yer tutar.

Değişen dünya ile beraber ülkemizde denizkum-güneş ekseninde gelişen turizm

faaliyetlerinin yerini, küçük ölçekli yerleşimlere doğru hareket eden bir yöneliş izlemektedir. $\mathrm{Bu}$ anlamda küçük yerleşim yerlerine olan ilginin arttırılması ve tanıtımının yapılması önemli bir yerde durmaktadır. Kültür turizmi için tarihi ve doğal mirasın korunması hayati bir öneme sahiptir (Eynehan, Numanoğlu\&Sabuncu, 2014. s.13).

Ülkemizde değişen turizm algısının küçük yerleşim yerlerine dönük başlayan ilerleyişi hızla gelişmekteyken kültürel mirasımızın korunması ve tanıtımının yapılması önemlidir. $\mathrm{Bu}$ bağlamda kentlerin özgün yapısına zarar vermeden oluşturulması gereken ve kültürel miras yönetimi planlamalarıyla geliştirilecek kültür rotaları küçük yerleşim yerlerinin tanıtımının yapılması açısından önemli bir yerde durmaktadir.

Yerleşim yerlerine özgü somut ve somut olmayan tüm kültürel miras ögelerini kapsayan gezi rotaları kurguları tüm dünyada gelişen kültür turizmi faaliyetlerini besleyecek bir yerde duracaktır.

\section{TURIZM ALGISI}

Günümüzde insanlar sürekli olarak ikamet ettikleri yerlerden geçici sürelerle ayrılarak başka ülke ve bölgelere gitmekte ve buralarda gezip görme, öğrenme ve dinlenme gibi sosyal, kültürel gereksinimlerini karşılamaktadırlar (Kalağan \& Yıldız, 2008. s.42). İnsanlık tarihinden bu yana var olan gezip görme isteği turizmin ortaya çıkmasına neden olmuştur.

Gürbüz'e göre turizm; “Devamlı olarak ikamet edilen yer dişına tüketici olarak tatil, dinlenme, eğlence, kültür vb. ihtiyaçların giderilmesi amacıyla yapılan seyahat ve geçici konaklama hareketleridir" (Gürbüz, 2002. s.50). 
Turizm ortama ve bulunduğu konuma göre değiş̧ebilen ve çeşitlenebilen, yöreye özgü alternatifleri olan özgün değerler taşımaktadır. $\mathrm{Bu}$ bağlamda turizm, içerisinde barındırdığ özellikleriyle insanların yaşam biçimlerine, tercihlerine ve ilgi alanlarına göre değişebilir.

Sosyal çevre ve yaşama olumlu etkileri olan turizm, insanların kültürel mirası yaşayarak tanıması ve kültürler arası farklılıkların tanınması gibi çok yönlü işlevleri barındırması açısından önemli bir araçtır.

Dünya'da turizm algısı değişmeye başlamış ve alternatif turizm faaliyetlerine doğru bir gelişim yaşanmıştır. Zamana paralel olarak farklı ilgi ve istekler doğrultusunda alternatif turizm gelişim göstermiştir.

\subsection{Alternatif Turizm}

Alternatif turizm 1980'lerde başlayarak kültürel miras ve sürdürülebilir gelişme ile birlikte adından söz edilir kavramlardan biri halindedir. Birçok araştırmacı alternatif turizmi doğaya duyarlı ve sürdürülebilir ilkelerle geliştirilen turizm çeşidi olarak yorumlamaktadır (Baytok, Pelit \& Soybalı, 2017. s.1).

Günümüzde insanların yoğun çalışma temposundan uzaklaşma isteği, stres ortamı ve nüfus artışından kaynaklı olarak sosyal alanların sınırlı hale gelmesi, şehirleşme içerisinde ise doğal yaşamın giderek azalması alternatif turizmin gelişmesine ve yeni alternatif turizm modellerinin ortaya çıkmasına neden olmaktadir.

Alternatif turizmin bir fikir olarak ortaya çıkmasında modernleşmenin etkisinden söz etmek mümkündür (Baytok vd., 2017. s.3).

Alternatif turizmin başlıca çıkış nedenleri üzerine çeşitli fikirler vardır:

- Kaynakların azalarak niteliklerinin bozulmas1,

- Sürdürülebilir turizm anlayışının ortaya çıkış1,

- Turizmin belli zaman dilimi sinırları içerisinden uzaklaşması,

- Tüketicilerin kıyı ekseninde gelişen deniz-kum-güneş turizminden sıkılması,
- İnsanların turizm faaliyetlerinde yeni arayışlara girmesi şeklindedir (Eker \& Zengin, 2014. s.4).

İnsanların günden güne değişen farklı istek, arzu ve beğenilere göre şekillenen alternatif turizm, sosyal ve kültürel kazanımları besleyen bir yerde durmaktadır. Yeni olanı arama isteği, farkl1 sosyal gruplarda veya ortamlarda bulunmak ve keşfetme duygusu alternatif turizmin çeşitliliğini arttırmış ve bu çeşitliliğin gelişimini önemli bir oranda etkilemiştir.

\subsubsection{Alternatif Turizm Çeşitleri}

Günümüzde insanların farklılığa ve yeniye olan ilgisi değișen bir turizm algısını ortaya çıkarmıştır. Bu anlamda alternatif turizm tek bir şeyi ifade ediyor olarak görünmesine rağmen içerisinde çok sayıda farklı türü ve çeşitliliği ifade eder.

Günümüzde turizm faaliyetlerinin belli yerlerle sınırlı kalması ve beraberinde yaratmış olduğu çevre tahribatı, insanların yeniye olan ilgisini arttırmıştır. Tüm bunlar alternatif turizm çeşitliliğinin ortaya çıkmasına neden olan en önemli unsurlardır (Kalağan \& Yıldız, 2008. s.43).

Alternatif turizm çeşitleri içerisinde günümüzde ilginin yoğun olarak yaşandığı kültür turizmi önemli bir yerde durmaktadır. Birleşmiş Milletler Dünya Turizm Örgütü (UNWTO) uluslararas1 turistlerin \%37'sinin kültür amaçlı seyahat ettiğini belirtmektedir (Öter \& Özdoğan, 2008. s.128).

Dünyadaki turizm trendleri ve ülkemizdeki kültürel çeşitlilik göz önüne alındığında kültür

turizminin ülkemizde turizm faaliyetlerinin gelişiminde ve çeşitlendirilmesinde önemli bir rol üstlenebileceği görülmektedir (Eynehan, Numanoğlu \& Sabuncu, 2014. s.12).

\subsubsection{Kültür Turizmi}

İnsanların farklı kültürleri tanımaya ve öğrenmeye olan istekleri kültür turizminin ortaya çıkmasını sağlamıştır. G. Richard kültür turiz-mini "Kişilerin kültürel ihtiyaçlarını gidermek amaçları ile bir yıldan az süre ile her zamanki yerlerinin dışında başka yerlere seyahat etmeleri" olarak tanımlamaktadır (Richard, 2005. s.21). 
Kültür turizmi, günümüz ve geçmiş kültürlere ait somut ve somut olmayan kültürel miras ögelerini görme, tanıma ve yaşayarak haklarında bilgi sahibi olabilmek amaciyla gerçekleştirilen ilgi turizmi olarak yorumlanmaktadır (Akkuş ve Güneş, 2016. s.75).

Kültür turizminin birçok farklı tanımı bulunmak-tadır. Genel bir tanıma ulaşmak zor olsa da kişiler ve toplum için ilerletici etkilerinin olduğunu söylemek yanlış olmayacaktır.

Tarihten bu yana farklı birçok medeniyete ev sahipliği yapmış ülkemiz, doğal güzellikler ve kültürel miras ögeleri bakımından zengin bir çeşitlilik barındırmaktadır. İnsanların farklı kültürleri tanıma isteği ve ilgi alanlarına dönük seyahat etme duygusu her geçen gün kültür turizmi faaliyetlerine olan ilgiyi arttırmaktadır.

Günümüz dünyasında insanlar yerel nitelikteki kültürleri tanımaya başlayarak bu yönde seyahatler geliştirmektedir. Örneğin günümüzde yerli ve yabancı turistler için çekim merkezi haline gelen gelenekselleşmiş ve yerel kültüre özgü olan 'Mersin Narenciye Festivali', 'Adana Portakal Festivali', 'Çanakkale Uluslararası Troia Festivali', 'Eskişehir Pişmiş Toprak Sempozyumu, 'Edirne Kakava Şenlikleri', 'Şarkışla Âşık Veysel Festivali' gibi örnekler bulunmaktadır.

Kişilerin yeni olanı arayışı ve kültürel farklılıklara yönelik ilgisi duygusal, düşünsel ve fikirsel anlamda katkılar sağlamaktadır. Aynı zamanda ziyaretçilerin estetik anlayışlarını geliştirmekte ve yeni kültürleri keşfetme, kültürel farklılıkları kazandırma noktasinda rol almaktadır.

\section{KÜLTÜREL MIRAASIN TURIZM AMAÇLARI}

Kültür ve Turizm bakanlığının tanımına göre kültürel miras "Bir toplumu diğer toplumlardan farklı kılan, geçmişten beri değişerek devam eden yaşayış ve düşünüş tarzı" şeklindedir. (www.kultur.gov.tr/ 13.04. 2018).

Somut kültürel miras (Taşınır, taşınmaz), somut olmayan kültürel miras, su altı kültürel miras1 ve doğal miras olarak dörde ayrılan kültürel miras ögeleri, toplumların kimliğini oluşturarak toplumların özgün değerlerini nesilden nesle aktarmakta tarihe 1şık tutar.

Kültürel mirasın turizm amaçlı kullanımının sosyal yap1 ve ekonomi üzerine büyük etkileri bulunmaktadır. Toplumsal yaşantı içerisinde insanların farklı kültürel ögeleri tanıması, sosyal ilişkiler geliştirmesi ve yaşam biçimlerini farklı kültürler ile buluşturması; ekonomik anlamda ise ülkelerin gelişmişlik seviyesini olumlu yönde etkilemesi, yöre halkına yeni istihdam olanakları sağlaması açısından katkılar sağlamaktadır.

\section{KÜLTÜREL MIRAS YÖNETIM PLANI}

Kültürel miras turizmi yönetim planları, turizmin giderek artan olumsuz etkilerini azaltmak, kazançları arttırmak, ziyaretçi ve çevre yöntimini sağlamak ve turizm organizasyonlarını düzenlemek gibi konular ile kültürel miras alanlarının planlanmasını kolaylaştıran araçlardır (Yıldız, 2011, s.41).

\subsection{Kültürel Miras Yönetimi}

Kültürel mirası sürdürülebilir kılmak ve tanıtımının yapılması amaciyla yönetim planlama süreçleri önem taşımaktadır. Kültürel miras yönetimi 19. ve 20. yüzyılda ortaya çıkmış bir yaklaşımdır. Tarihi miras yapılarının ve anit eserlerin korunması, değişen dünya karşısında önem arz ederek tahribata karş1 bir koruma yönteminin geliştirilmesi amacıyla önem kazanmıştır. $\mathrm{Bu}$ durum kültürel mirasın yönetim konusu olarak ortaya çıkışının en önemli nedenidir (Aksoy vd., 2012. s.9).

Kültürel mirasın korunması ve bu korumanın yönetilmesinin sürdürülebilir olabilmesi için yönetim planı, kültürel mirası günlük hayatımıza dâhil etme, ekonomik bir boyut kazandırma ve gelecek nesillere bu olguları taşıma amacı içerisinde düşünülmekte ve ilerlemektedir. (Kuşçuoğlu\&Taş, 2017. s.64).

Kültürel miras yönetimi tüm miras ögeleri açısından önemli bir yönetim aracıdır. Alana özgü ve hedefe yönelik yapılacak yönetim planlamaları, kültürel değerleri korurken aynı zamanda toplum ile buluşturacaktır. 


\subsection{Ziyaretçi Yönetimi}

Ziyaretçi yönetimi insan aklının bir düzenlenmesi ve farklı gruplardaki insanları idare etmeye yönelik bir yönetim sürecidir (Tandoğdu, 2015. s.29).

Kültür turizmi göz önüne alındığında kültürel miras ve ziyaretçiler karşılıklı gelişen bir ilişki içerisindedir. $\mathrm{Bu}$ anlamda kültürel miras yönetimi planlamaları gerçekleşirken ziyaretçi yönetimi göz önüne alınmalıdır.

Kültürel miras alanlarında ziyaretçilerin deneyim kazanmaları, kültür turizmini geliştirerek ziyaretçilerin kalitesini maksimuma çıkaracak yönetim bölümüdür (Y1ldı, 2011.s.53).

Kültürel miras yönetimi alanında kültür turizminin gelişmesinde ziyaretçi yönetimini etkileyecek stratejiler şu şekilde sıralanabilir:

- Bir bölgedeki insan sayısını tek bir yerde toplamak ya da alana dağıtmak,

- Etkinlikleri gösterecek yolları işaretlemek ve etkinlik çeşitliliklerini arttırmak amacı ile katılımcisı olmayan etkinlik çeşitlerinde değiştirmeye gitmek,

- Bir yörenin ya da alanın çevresinde fiziksel engeller varsa değişikliğe gitmek ve yol, alt yapı vb. düzenlemeler yapmak,

- Bir yörede ya da alanda ziyaretçi akışından dolayı oluşabilecek olumsuzluklara karşı ziyaretçiler ve yerel halk arasında çözüm odaklı planlamalar geliştirmek,

- Alan yöneticileri tarafından ziyaretçileri belli etkinlikler çerçevesinde teşvik etmek ve katılım arttırıc1 faaliyetlerin sürmesini sağlamak,

- Açılış saatlerinde düzenlemelere giderek saat kısitlamaları yapmak ve farklı ziyaretçilerin alana dönük katılımlarını arttırmak,

- Gelir düzeyine göre ziyaretçi etkinlikleri-nin çeşitlilik barındırmasını sağlamak,

- Olumsuzluk yaratacak etkinlikleri yasal düzenlemelerle yasaklamak şeklindedir (Y1ldiz,2011.s.56)
Etkin bir şekilde sağlanacak ziyaretçi yönetimi ziyaretçilere kültürel duyarlılığın sağlanması, toplumsal bilinç, estetik anlayışı ve entelektüel anlamda büyük katkılar sunacaktır.

\section{METODOLOJI}

Araştrmanın teorik alt yapısını oluşturması amaciyla kültürel miras, alternatif turizm, kültür turizmi, kültürel miras yönetimi, ziyaretçi yönetimi, kültürel miras rotas1 kavramları araştırılmıştır. $\mathrm{Bu}$ anlamda çalışmada literatür araştırması yöntemi izlenmiştir. Çalışmada ülkemizden ve dünyadan örnekler incelenerek araştırmada sunulan kültür rotaları önerisine cevaplar aranmıştır.

\section{ROTA NEDİR? NASIL KURGULANMALIDIR?}

Son yıllarda turistlerin bozulmamış, doğal ortamlara ve kültürel miras alanlarına olan ilgisi, turizm işletmelerinin daha fazla turist çekebilmek için ürün çeşitlendirmeye yönelik çalışmaları, ulusal turizm örgütleri ve kamu yerel yönetimlerinin alternatif turizm mekânları oluşturma yönünde planlamaları "Turizm Rotaları/Güzergâhları" kavramını gündeme getirmiştir (Kervankıran \& Çuhadar, 2014. s.578).

Geçmişte askeri, dini, ticari ve sosyal amaçlarla kullanılmış ulaşım güzergâhları günümüzde turizm faaliyetleri içerisinde kullanılmaktadır. Gelişen kültür turizmi ile birlikte kültürel mirasın tanıtımında bu güzergâhlar önem taşımaktadır.

Günümüzde uluslararası kuruluşlar tarafindan güzergâh kavramı "Kültürel Rota" şeklinde tanımlanır (Çekül Vakfı, 2015. s.12).

Her kentin kendine ait bir kimliği vardır. Kültür mirasının rotalar ile kurgulanması kent kimliğinin ön plana çıkarılması adına önem taşımaktadır.

Kültür rotalarının kurgusu gerçekleştirilirken kültürel miras ögelerinin özellikli noktaları çok önemlidir. Kişilerin yaş grubu, ilgi alanları, beklentileri, eğitim durumları vb. birçok konu düşünülüp çok yönlü bir rota kurgusu geliştirilmelidir. Kente, yöreye ait olan ne varsa rota içerisine almalı ve toplayıcı olmalıdır. Örneğin; alışveriş kültürü, yemek kültürü, müzik kültürü vb. bir kent için 
oluşturulacak rota içerisinde mutlaka yer almalıdır.

\subsection{Küçük Yerleşimlerde Kültürel Miras Rotasi Kurgularken Dikkat Edilmesi Gerekenler}

Günümüzde kültür turizmi alternatif turizm modellerini içine almıştır. Değişen turizm anlayışı beraberinde kültür turizmine akışı arttırmıştır. $\mathrm{Bu}$ artış küçük yerleşim yerlerinde de kendini göstermiştir. Ekolojik turizm faaliyetleri, macera turizmi, kültür turizmi gibi birçok alternatif turizm çeşiti değişen turizm algisı ile beraber küçük yerleşimlere kaymaktadır.

Küçük yerleşim yerlerinde kültürel miras rotas1 kurgulanmas1;

- Kültürel kimlik konusunda toplumun bilinçlendirilerek tarihi değerleri paylaşmak ve kültür mirası bilincinin yerleşmesini sağlaması,

- Farklı kültürleri tanımayı ve farklı kültürlerle sosyal ilişki ve etkileşimi geliştirmesi,

- Küçük yerleşim yerlerinde yeni istihdam olanaklarının gelişmesi, gelişmelerden kaynaklı olarak yöre halkının yaşam kalitesini arttırmas1,

- İnsanların yaşayarak öğrenmesi ve bilgi birikiminin geliştirmesi.

- Küçük yerleşim yerlerinin farkındalığının artmasını sağlar.

Küçük yerleşim yerlerinde kültür rotaları kurgularken dikkat edilmesi gereken bazı unsurlar şu şekildedir:

- Ziyaretçi akışından kaynaklanabilecek doğal kaynakların kullanımı,

- Yöreyi oluşturan doğal çevrenin tahribatının önlenmesi,

- Etkileşimden kaynaklı olarak yerel halkın özgün niteliğinin korunması,

- Somut kültürel mirasımızın tahribata neden olabilecek her türlü unsurdan kaçınılarak korunması,

- Kültürel miras yönetimi ve ziyaretçi yönetimi çok iyi uygulanmalıdır.

\section{SONUC VE ÖNERILER}

Günümüzde turizm anlayışı değişmeye başlamıştır. Turizm artık kendisini alternatif turizme açarken kültür turizmi ise somut ve somut olmayan kültürel miras ögeleriyle beraber alternatif turizm modellerinin tümünü içerisine alarak bir model oluşturmaktadır. $\mathrm{Bu}$ anlamda kültür turizminin tüm alternatif turizmi içine toplayabilecek niteliği vardır. Alternatif turizmi yorumlarken yarattığ 1 tek başınalıktan çıkararak bütünleşik değerlendirmemiz gerekmektedir.

Değișen turizm algısıyla beraber büyük ölçekli kentlere olan ilginin günden güne küçük ölçekli kentlere doğru geçişi söz konusudur. $\mathrm{Bu}$ anlamda kentlerin kendine özgü özelliklerini koruyan ve tanıtılmasını sağlayan bütünleşik bir kurgu olarak kültür rotalarının oluşturulması önemlidir.

Rotalar oluşturulurken kültürel mirasın özellikli noktalarının tespiti önemlidir. Kentlerin geleneksel özelliklerini içerisinde barındıran anıtsal eserler, gelenekler; kültürel ögeleri olarak yemek kültürü, alışveriş kültürü, giyim kültürü, müzik kültürü, doğal güzellikleri gibi tüm katmanları kentlerin kimliğini ön plana çıkaran özellikleridir. Bunlar kültür rotaları içerisinde kurgulanmasına açık özelliklerdir. Bu anlamda rotalar tüm bu kurguyu hissettirebilecek şekilde olmalıdır.

Rotalar kurgulanırken ziyaretçi yönetimi konusu iyi planlamalı, ziyaretçilerin kentin özgün değerlerine zarar vermeden turizm faaliyeti içerisinde yer alacağı bir planlama geliştirilmelidir.

Küçük yerleşim yerlerinin kültür rotaları ile tanıtımının yapılmasında, yerel işletmecilere yöreye özgü değerleri barındıran faaliyetlerini arttırıcı teşvikler verilmelidir. Ayrıca yerleşim yerlerindeki yöneticilerin yerel işletmecilerin, ziyaretçilerin ve yerel halkın oluşturabileceği tahribata karş1 bilinçlendirmeye yöntelik faaliyetler geliştirmesi ve önlemler alması önerilmektedir. 


\section{KAYNAKÇA}

Akkuş, O. Güneş, G. (2016). Mersin Aydıncık İlçesi Ve Çevresinin Kültür Turizmi Potansiyeli Açısından Değerlendirilmesi. AİÜ Sosyal Billimler Enstitüsü Dergisi. Cilt:16, Say1:2,16:7398.

Aksoy, A. Enlil, Z. Ünsal, D. Pulhan, G. Dinçer, İ. Gülersoy, N.Z. Ahunbay, Z. Köksal, G. (2012) Kültürel Miras Yönetimi. Açıköğretim Fakültesi Yayını. No:1543.

Albayrak, A. (2013). Alternatif Turizm. Ankara: Detay Yayınc1lık.

Bahçe, S.A. (2009) Kırsal Gelişimde Kültür Mirası Turizmi Modeli. Dumlupınar Üniversitesi, Sosyal Bilimler Dergisi. Sayı:25.

Baytok, A. Pelit, E. Soybalı,H.H. (2017) Alternatif Turizm mi Turizmde Çeşitlilik Mi? Kavramsal Bir Değerlendirme. Erzincan Üniversitesi Sosyal Bilimler Enstitüsü Dergisi (ERZSOSDE) IV:1-14.

ÇEKÜL Vakfı (2015). Kültür Rotaları Planlama Rehberi. Tarihi Kentler Birliği Yayınları, Kılavuz Kitapçıklar Dizisi: 3, Çekül VakfıTarihi Kentler Birliği, İstanbul.

Eynehan, M.E. Numanoğlu, N. Sabuncu,T.B. (2014) Türkiye'de Alternatif Turizmin Gelişimine Yönelik Değerlendirmeler. TÜSİAD. 09/556.

Eker, N. Zengin, B. (2014) Alternatif Turizm Kapsamında Kültür Turizminin Sürdürülebilirliğinde Turist Rehberlerinin Rolü: Bir Uygulama. XIII. Geleneksel Turizm Paneli.

Gürbüz, A. (2002) Turizmin Sosyal Çevreye Etkisi Üzerine Bir Araştırma. Teknoloji. Y11:5, Say1: 1-2.

Kalağan, G. Yıldız, Z. (2008) Alternatif Turizm Kavramı ve Çevresel Etkileri. Yerel Siyaset Dergisi.

Kervankıran, İ. Çuhadar, M. (2014) Turizm Rotalarının Oluşturulmasında Coğrafi bilgi Sistemlerinin Önemi. III. Disiplinlerarası Turizm Araştırmaları Kongresi.

Kuşçuoğlu, G.Ö. Taş, M. (2017) Sürdürülebilir Kültürel Miras Yönetimi. Süleyman Demirel Üniversitesi Yalvaç Akademi Dergisi. 2 (1): 58-67.

Öter, Z. Özdoğan,O.N. (2005) Kültür Amaçlı Seyahat Eden Turistlerde Destinasyon İmaj1: Efes Selçuk Örneği. Anatolia: Turizm Araştırmaları Dergisi. Cilt:16. Sayı:2.
Richards, G. (2005) Cultural Tourism in Europe. Atlas, Wallingford, Oxford.

Tandoğdu, H.İ. (2015) Tarihi Anıt Ve Sitlerde Önleyici Koruma Olarak Zİyaretçi Yönetimi: Topkapı Sarayı Müzesi Örneği. Yüksek Lisans Tezi. İstanbul: İstanbul Teknik Üniversitesi, Fen Bilimleri Enstitüsü, Mimarlık Ana Bilim Dalı.

Yıldız, S. (2011) Kültürel Miras Alan Yönetimi Kapsaminda Alanya Kalesi Ziyaretçi Yönetimi. Doktora Tezi, Antalya: Akdeniz Üniversitesi, Sosyal Bilimler Enstitüsü, Turizm İşletmeciliği ve Otelcilik Ana Bilim Dall.

www.kultur.gov.tr (13-04-2018). 